\title{
Decreased Staphylococcus aureus biofilm formation on nanomodified endotracheal tubes: a dynamic airway model
}

\author{
Mary C Machado' \\ Keiko M Tarquinio ${ }^{2}$ \\ Thomas J Webster ${ }^{3}$ \\ 'School of Engineering, Brown \\ University, Providence, RI; ${ }^{2}$ Division \\ of Pediatric Critical Care Medicine, \\ Rhode Island Hospital, Providence, \\ $\mathrm{RI} ;{ }^{3} \mathrm{School}$ of Engineering and \\ Department of Orthopedics, Brown \\ University, Providence, RI, USA
}

Correspondence: Thomas J Webster I 84 Hope St, Providence, RI 029I2, USA $\mathrm{Tel}+\mathrm{I} 4018632318$

Email thomas_webster@brown.edu
This article was published in the following Dove Press journal:

International Journal of Nanomedicine

13 July 2012

Number of times this article has been viewed

\begin{abstract}
Ventilator-associated pneumonia (VAP) is a serious and costly clinical problem. Specifically, receiving mechanical ventilation for over 24 hours increases the risk of VAP and is associated with high morbidity, mortality, and medical costs. Cost-effective endotracheal tubes (ETTs) that are resistant to bacterial infections could help prevent this problem. The objective of this study was to determine differences in the growth of Staphylococcus aureus on nanomodified and unmodified polyvinyl chloride (PVC) ETTs under dynamic airway conditions simulating a ventilated patient. PVC ETTs were modified to have nanometer surface features by soaking them in Rhizopus arrhisus, a fungal lipase. Twenty-four-hour experiments (supported by computational models) showed that airflow conditions within the ETT influenced both the location and the concentration of bacterial growth on the ETTs, especially within areas of tube curvature. More importantly, experiments revealed a $1.5 \mathrm{log}$ reduction in the total number of $S$. aureus on the novel nanomodified ETTs compared with the conventional ETTs after 24 hours of airflow. This dynamic study showed that lipase etching can create nanorough surface features on PVC ETTs that suppress $S$. aureus growth, and thus may provide clinicians with an effective and inexpensive tool to combat VAP.
\end{abstract}

Keywords: biofilm, laminar flow, ventilator-associated pneumonia, nanotechnology, endotracheal tubes, S. aureus

\section{Introduction}

The prevention of ventilator-associated pneumonia (VAP) is of great importance in modern medicine. VAP is the second most common hospital-acquired infection among pediatric intensive care units and results in increased mortality, morbidity, and medical costs. ${ }^{1,2}$ VAP is particularly difficult to diagnose in pediatric patients, leading to delays in targeted treatment. ${ }^{3,4}$ It also increases hospital stays by an average of 8.7 days and can increase hospital costs by up to $\$ 51,157 .^{2}$ The two pathogens most commonly associated with VAP in pediatrics are Pseudomonas aeruginosa and Staphylococcus aureus. ${ }^{5}$

One of the main sources of bacterial colonization within the airway is the endotracheal tube (ETT). ETTs are of special concern because these tubes provide a direct conduit from the outside environment to the lungs. ${ }^{6}$ A key problem for inhibiting bacterial growth on ETTs occurs when bacteria exude an exopolysaccharide, which adheres bacteria together. Bacteria in this type of extracellular matrix (known as a biofilm) are especially resistant to both antibiotics and the immune system of the patient. ${ }^{7}$ Ventilation through such colonized ETTs, or even condensation of humidified air, can break off 
portions of the biofilm, bringing bacteria deeper into the lungs and spurring growth on other areas of the tube. ${ }^{8}$

The unique properties of nanomodified surfaces (or surfaces with features $<100 \mathrm{~nm}$ in one direction $)^{9}$ could provide a solution to the persistent problems of VAP. ${ }^{9-15}$ Micro- and nanoscale building blocks form the foundation for cells and tissues within the human body. ${ }^{16}$ Nanomaterials have unique surface energetics due to their significantly greater surface area compared with conventional nanosmooth materials. Such changes in surface energy undoubtedly influence initial protein interactions that are important for mediating bacterial adhesion. ${ }^{17}$ One of the first steps within the process of cell adhesion is the association between proteins adsorbed on implant surfaces and cell membrane receptors. The large surface to volume ratio characteristics of nanomaterials have been shown to affect this association to inhibit bacteria attachment and promote nonbacterial cell (such as osteoblasts, smooth muscle cells, endothelial cells, chondrocytes) adhesion. ${ }^{18-21}$ The type, concentration, conformation, and bioactivity of proteins adsorbed onto a material depends on its surface chemistry, hydrophilicity, charge, topography, roughness, and energy, all of which can be influenced by nanotechnology. ${ }^{22}$ Surface properties, including roughness, stiffness, and topography, also affect bacterial adhesion and may play an important role in the initial stages of biofilm formation. ${ }^{23-25}$ Reducing bacterial adhesion and biofilm formation on the surface of an ETT could reduce further colonization of the ETT.

Moreover, previous studies on VAP have concentrated on biofilm formation in straight, adult ETTs under static conditions. However, fluid and air within curved tubes, like ETTs, display unique secondary flows. ${ }^{26}$ Biofilms can alter their structural properties in response to fluid effects (such as shear stress or vortical flows), both resisting detachment and facilitating further colonization. 25,27,28

The objective of this in vitro study was to fabricate and test nanomodified ETTs (without the use of antibacterials), under simulated dynamic airflow conditions of the respiratory system, in order to determine their antimicrobial effectiveness. To achieve this, both experimental and computational analyses were performed.

\section{Materials and methods Nanomodification of ETTs}

The first type of antibacterial ETT prepared for analysis within our system was a polyvinyl chloride (PVC) ETT (Sheridan $^{\circledR}$, Teflex Medical, Arlington Heights, IL) with nanoroughened surfaces. These tubes were transformed to have nanofeatures using lipases from the fungi Rhizopus arrhisus
(Sigma-Aldrich, St Louis, MO), which enzymatically degrade the PVC material. The procedure included exposing the PVC tubing to a $0.1 \%$ mass solution of $R$. arrhisus lipase dissolved in a potassium phosphate buffer at $37^{\circ} \mathrm{C}$. The samples were gently agitated for a total of 48 hours, and the lipase medium was changed every 24 hours.

The activity of the $R$. arrhisus lipase used in the experiment was $10.5 \mathrm{U} / \mathrm{g}$, where one unit was defined as the amount of enzyme that catalyzed the release of $1 \mu \mathrm{moL}$ of oleic acid per minute at $\mathrm{pH} 7.4$ and $40^{\circ} \mathrm{C}$. ETTs placed within the system were modified on both the inner and outer surfaces. ETTs were sterilized using ethylene oxide exposure in a 16-hour sterilization cycle.

\section{Material characterization}

Each of the samples was coated with a gold palladium mixture to increase conductivity for scanning electron microscopy (SEM) (LEO 1530VP FE-4800 Field-Emission SEM, Carl Zeiss SMT, Peabody, MA) in order to visually assess nanometer surface features. Nanoroughness was also assessed using an atomic force microscope (AFM) (XE-100, Park Systems, Santa Clara, CA) under tapping mode using a $10 \mathrm{~nm}$ AFM tip (PPP-NCHR, Park Systems) with a scan rate of $0.5 \mathrm{~Hz}$. The roughness of each of the surfaces was quantified by an AFM using root mean square roughness. Contact angle data were assessed to determine surface hydrophobicity (EasyDrop DSA20S, Kruss, Hamburg, Germany). Characterization of the elemental composition of the nanomodified and control ETTs was also conducted by x-ray photoelectron spectroscopy (XPS) (5500 Multitechnique Surface Analyzer, Perkin Elmer, Waltham, MA).

As proteins mediate bacteria attachment, a BCA Protein Assay Kit (Thermo Scientific, Rockford, IL) was used to quantify the total amount of protein adsorbed on the samples. This was accomplished by soaking sterilized ETT tube pieces in trypticase soy broth (TSB) medium for 10 hours. This TSB medium was then tested to determine the total amount of protein in each sample. Additionally, to test protein adsorption on the surfaces of the tube, ETT pieces were then removed from the TSB medium and resuspended in phosphate buffered saline with RIPA buffer, which removes adsorbed proteins. The total amount of proteins in the supernatant was then tested using the BCA assay following manufacturer's instructions.

\section{Bacteria dynamic testing in a bench-top airway model}

Nanomodified ETTs were tested in a custom-made benchtop model airway adapted from the general design of 
Hartmann et al. ${ }^{29}$ This model airway can be seen in Figure 1. ETTs with a $3.5 \mathrm{~mm}$ internal diameter were placed in the system. The boxes were then filled with sterile TSB medium and placed in a water bath that was maintained at $37^{\circ} \mathrm{C}$. An ETT was connected to an Infant Star 950 ventilator (Puritan Bennett, Covidien, Mansfield, MA), with positive end-expiratory pressure of $1 \mathrm{cmH}_{2} \mathrm{O}$ and fraction of inspired oxygen $\left(\mathrm{FiO}_{2}\right)$ of 0.5 . A total of $480 \mathrm{~mL}$ of TSB was inoculated with $10^{3}$ colony-forming units (CFUs) $/ \mathrm{mL}$ of $S$. aureus (ATCC \#25923). This bacterial medium was then circulated into the oropharynx box over the duration of a 24-hour test, using a peristaltic pump. Sterilization tests were performed routinely to detect any cross-contamination. For each run, an ETT was added to the sterilized oropharynx and lung boxes.

In addition, at the end of each trial, ETTs were cut into ten $1.5 \mathrm{~cm}$ pieces. These tubes were either stained with crystal violet and analyzed for optical density using a spectrophotometer (Spectramax 340PC384, Molecular Devices, Sunnyvale, CA) or processed using a vortex protocol to determine the number of CFUs. The vortex protocol consisted of adding the ETT pieces to $2 \mathrm{~mL}$ of TSB medium and vortexing the ETTs for 1 minute at $3000 \mathrm{rpm}$ (Digital Vortex Mixer, Fisher Scientific, Pittsburgh, PA). The supernatant was then serially diluted and plated. Colony counts were performed to determine the number of bacteria on each area of the tube.

\section{Airflow analysis}

To fully understand the dynamic airflow conditions within this system that may influence bacteria functions, further analysis of the fluid effects of ETT orientation was conducted by graphing the curved tubes by hand, and then was reassessed by analyzing the curvature of the three-dimensional model in SolidWorks (2010, Dassault Systèmes, VélizyVillacoublay, France). Jarreau et $\mathrm{al}^{30}$ reported that the mean range of ETT curvature diameters from magnetic resonance imaging scans were $8-18 \mathrm{~cm}$ with a $<16 \%$ variation in pressure between these extremes. Both of the studied curves present in the ETT, which can be seen in Figure $2,{ }^{31}$ were within these parameters. The radius of curvature $\left(R_{c}\right)$ of the first curve measured about $18 \mathrm{~cm}$, whereas the $R_{c}$ of the second curve was $9 \mathrm{~cm}$.

To evaluate the Navier-Stokes equations for the curved ETTs, the secondary axial motion of the fluid within the tube bends must be taken into account. Using the velocity measured from the ventilator $(6.93 \mathrm{~m} / \mathrm{s})$, the Reynolds number was evaluated with the following equation where $\bar{u}$ is the mean average velocity, $D$ is the diameter of the tube, and $v$ is the kinematic viscosity of air. Within the ETTs, the Reynolds number was found to be 1455 , which placed the flow in the system in the laminar range.

$$
\operatorname{Re}=\frac{\bar{u} D}{v}
$$

Due to the unique conditions within the system, further calculations were needed. Flow in curved tubes is much more stable than that of a straight pipe; thus, the transition from laminar to turbulent has been shown to be much higher than the usual value of 2300, sometimes by even a factor of 2 or more. ${ }^{32}$ To better evaluate the computational model, the critical Reynold's number was calculated according to the following formula proposed in Jarreau et al, where D is the diameter of the tube and $R_{c}$ is the radius of curvature. ${ }^{30}$ The critical Reynolds number is 5668 .

$$
\operatorname{Re}_{c}=20,000 *\left(\frac{D}{2 R_{c}}\right)^{0.23}
$$
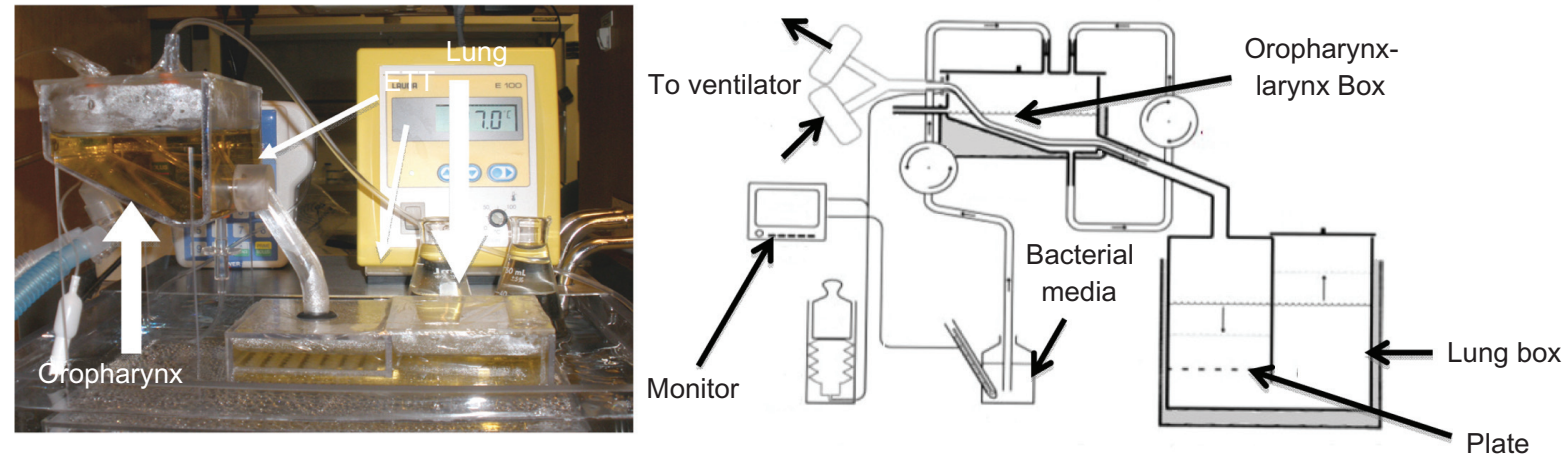

Figure I Model of the endotracheal tube (ETT) system used in this study. ${ }^{29}$ 


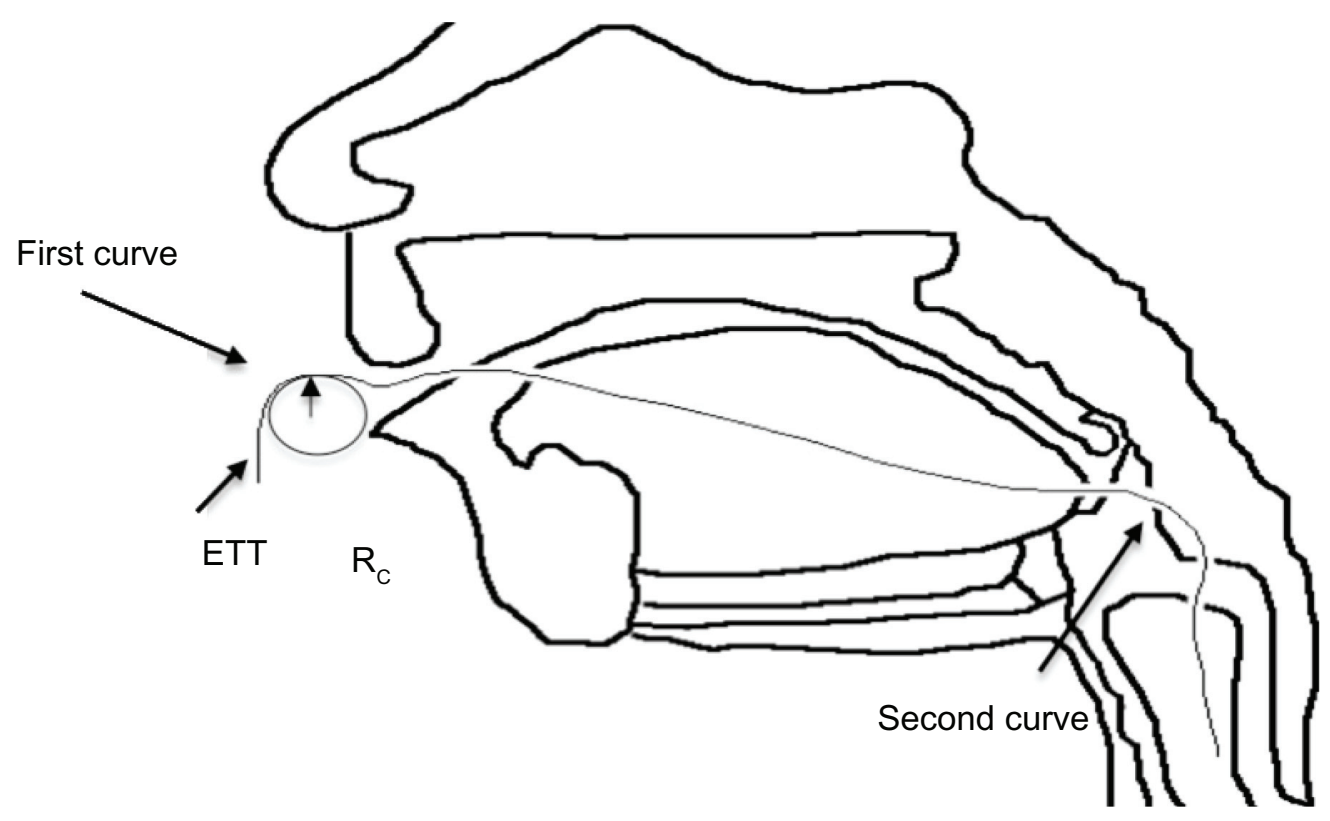

Figure 2 Diagram of endotracheal tube (ETT) curvature. ${ }^{31}$

The approximations for the fluid model also assumed quasistatic flow in the ETT. To determine whether this approximation was appropriate, the Womersley parameter was calculated for the ETT.

$$
\alpha=\frac{d}{2} \sqrt{\frac{\omega}{v}}
$$

Where $d$ is the diameter of the tube, $\omega$ is angular velocity $(2 \pi f[\mathrm{rad} / \mathrm{s}])$ where $f$ is the frequency of the ventilator in $\mathrm{Hz}$, and $v$ is the kinematic viscosity of air. If $\alpha<16$, the flow can be approximated as quasisteady. ${ }^{30}$ The Womersley parameter for the ETTs in the lung box system was 0.16 .

The final part of the present airflow analysis of the ETT consisted of the creation of a three-dimensional computational model. A finite element model of the exact curvature of the ETTs was created using COMSOL Multiphysics (v4.0a, COMSOL Group, Burlington, MA). Airflow through the ETT was considered to be laminar, Newtonian, and incompressible. The unsteady, three-dimensional form of the Navier-Stokes equations was then solved using the finite element method. For this flow model, the boundary conditions prescribed over the domain were as follows: (1) on the solid wall of the tube a no slip condition was applied; (2) an absolute pressure of $1 \mathrm{~atm}$ was assumed at the outlet, as is common within the clinical setting; and (3) finally, the inlet pressure for a pressure-limited, constant flow ventilator was represented using a square wave, as seen in the literature. ${ }^{33}$ The upper limit of the square wave was the positive inspiratory pressure minus the positive end-expiratory pressure, whereas the lower limit was $1 \mathrm{~atm}$. Each peak was exactly 0.416 seconds wide, the inspiratory time of the ventilator.

The initial conditions for the model were as follows: (1) the initial inlet velocity was set at $0 \mathrm{~m} / \mathrm{s}$ and (2) the initial inlet pressure was set at $1 \mathrm{~atm}$.

To gain a better understanding of the bacterial dispersion within the system, a Lagrangian particle tracing model was performed using COMSOL Multiphysics, where all particles were assumed to be a single bacterium. Both drag and gravitational force were included in this one-way fluid particle coupling, and the particles (bacterium) were considered to move with the flow in the tube. The diameter of each particle (bacterium) was taken as $1 \mu \mathrm{m},{ }^{34}$ whereas the mass was taken as $1 \mathrm{pg} .{ }^{35}$ All particles that touched the wall of the tube were considered trapped, and no reflection occurred within this model. Particles were released at the inlet of the ETT.

Residence time of the particles was calculated from particle position and velocity data found in COMSOL Multiphysics. Multiple simulations were performed, with each simulation containing at least three breathing cycles.

\section{Statistical analysis}

All experiments in the system were performed three times $(\mathrm{N}=3)$, and the results were reported as mean \pm standard error of the mean. Analysis of variance statistical analysis was performed on all results. 


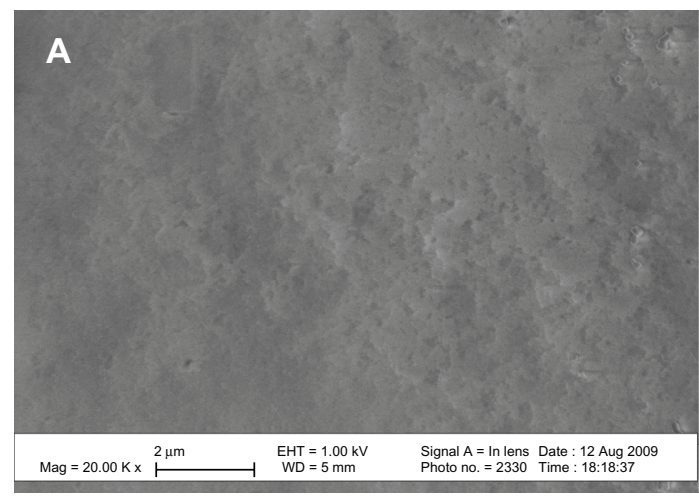

Figure 3 Scanning electron microscopy images of nanomodified and untreated polyvinyl chloride endotracheal tubes. (A) Nano-R: mag $\times 20 \mathrm{~K}$. (B) Untreated: mag $\times 30 \mathrm{~K}$. Nano-R was modified with Rhizopus arrhisus.

Note: Scale bars $=2 \mu \mathrm{m}$.

\section{Results}

\section{Material characterization}

PVC ETTs cut and submersed in the lipase solution $R$. arrhisus showed visible nanofeatures (Figure 3). In contrast, control untreated PVC ETTs did not show any nanofeatures.

AFM analysis of the nanomodified ETTs confirmed SEM analysis (Figure 4). The average root mean square roughness of the ETTs nanomodified with $R$. arrhisus was $12.5 \mathrm{~nm}$ compared with a value of $2.2 \mathrm{~nm}$ for the untreated PVC tubes; AFM scans were $5 \times 5 \mu \mathrm{m}$ for this analysis. XPS data can be seen in Figure 5 for the nanomodified tubes. This showed no change in chemical composition of the ETTs modified with Nano-R compared with untreated ETTs.

Surface energy analysis for the nanomodified PVC was also performed and can be seen in Figure 6. Results showed a water contact angle of $84.4^{\circ}$ for the unmodified PVC and an angle of $68.9^{\circ}$ for the $R$. arrhisus-treated (Nano-R) samples. Thus, Nano-R possessed increased hydrophilicity.

The BCA assay showed an increased amount of protein adsorption on the nanomodified (Nano-R) samples compared with the untreated PVC (Figure 7), corresponding to the increased hydrophilicity of these surfaces.

\section{Dynamic testing in a bench-top model}

For the present analysis, 24-hour studies performed in a dynamic airflow chamber showed a marked difference in biofilm formation on the different areas of the unmodified ETTs (Figures 8 and 9). Areas of ETT curvature, such as at the entrance to the mouth and the connection between the oropharynx and the larynx, were correlated with larger amounts of biofilm formation. Crystal violet staining revealed round patches in these regions. Most importantly, CFUs were significantly smaller (up to a $1.5 \log$ reduction) on the nanomodified ETTs than on control ETTs, all achieved again without the use of pharmaceutical drugs.

\section{Fluid analysis}

Computational model results seen in Figure 10 showed skewing of the air velocity profile at both curves in the ETTs ( $b$ and c), with consequent variations in the wall shear rates along the
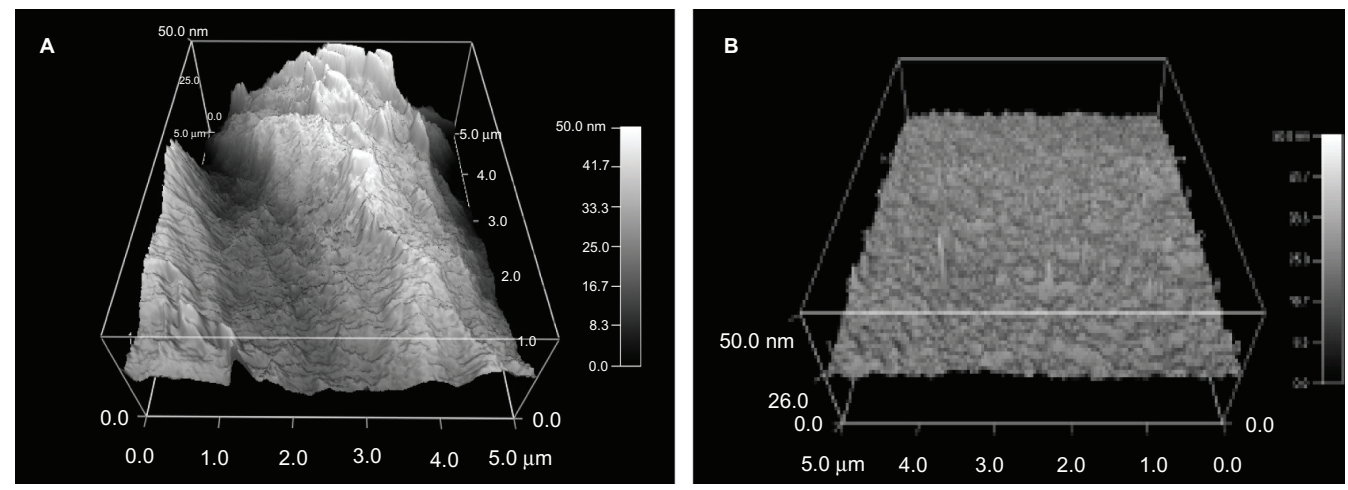

Figure 4 Atomic force microscopy images of polyvinyl chloride endotracheal tubes treated with (A) $0.1 \%$ Rhizopus arrhisus solution (Nano-R) for 48 hours compared with (B) untreated polyvinyl chloride samples. 

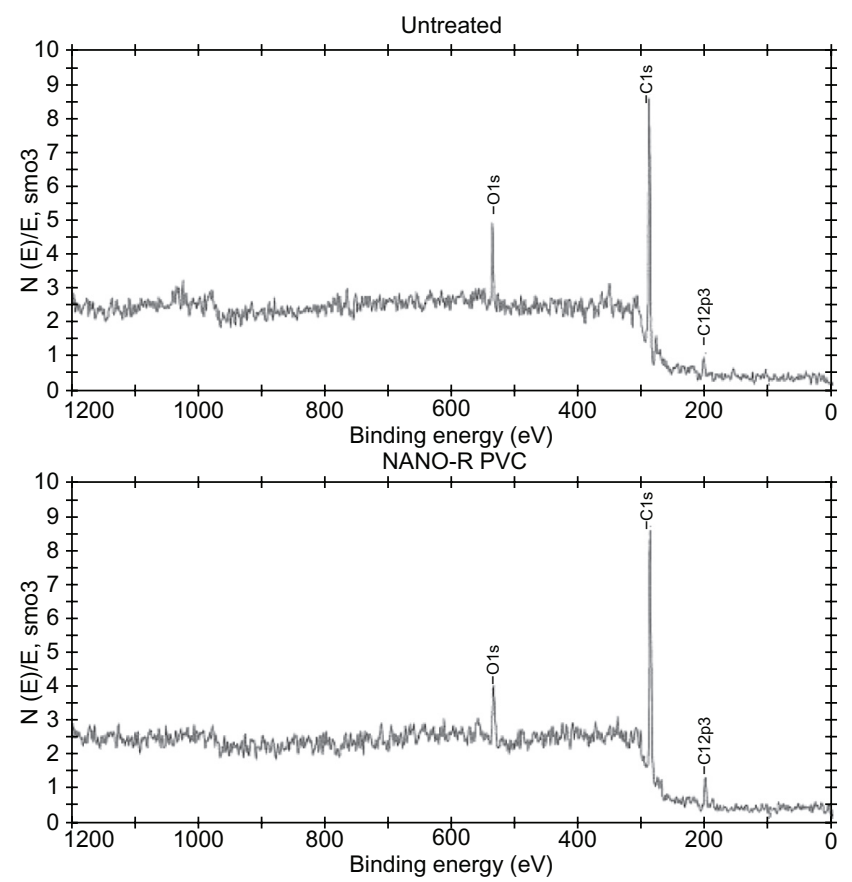

Figure 5 X-ray photoelectron spectroscopy of nanomodified and untreated polyvinyl chloride (PVC) endotracheal tubes (Nano-R). Nano-R was modified with Rhizopus arrhisus.

ETT. A correlation coefficient between shear and bacterial density of about 0.37 was found for both treated and untreated ETTs. This suggests that factors other than changes in shear stress (such as bacteria residence time, secondary velocity, and interactions with the wall) are important to understand differences in bacterial distribution along the ETTs.

To further investigate these effects, an associated Lagrangian particle analysis was performed, the results of which can be seen in Figures 11 and 12, where the final particle (bacterium) location is graphed with bacteria distribution. A weak correlation coefficient of 0.50 was found for the untreated ETTs and 0.52 for the nanomodified ETTs. This suggests that some other factor than the velocity flow field and forces on the bacteria in the curved portions of the tube plays a dominant role in determining bacterial distribution. These effects will be further investigated in future tests.

\section{Discussion}

Similar to previous static studies, ${ }^{10,36}$ results from this study showed significant reductions in the number of CFUs on the nanomodified ETTs. The difference between crystal violet and colony counts was thought to be a result of a combination of increased extracellular polymeric material on the nanomodified surfaces and the reaction of the nanomodified surfaces with the crystal violet dye. To mitigate these effects, optical density values from ETTs modified with Nano-R and stained with crystal violet were subtracted from the bacteria-cultured ETTs stained with crystal violet. Both the results of the optical density tests and the values of the modified ETT blanks can be seen in Figure 8.

Notably, the dynamic values for biofilm density along many areas of the ETT were substantially less than the values obtained in previous static studies ${ }^{10}$ on the same samples, thus illustrating the importance of the dynamic analysis of ETTs. This reduction in the number of bacteria seen on the ETTs under dynamic flow could be due to the morphological changes of the biofilm in response to shear stress. Physical

\begin{tabular}{|c|c|c|}
\hline & Untreated & Nano-R \\
\hline Sample pictures & & \\
\hline Water contact angle & 84.4 & 68.9 \\
\hline
\end{tabular}

Figure 6 Increased hydrophilicity of nanomodified polyvinyl chloride endotracheal tubes (Nano-R) compared with controls. Nano-R was modified with Rhizopus arrhisus. 


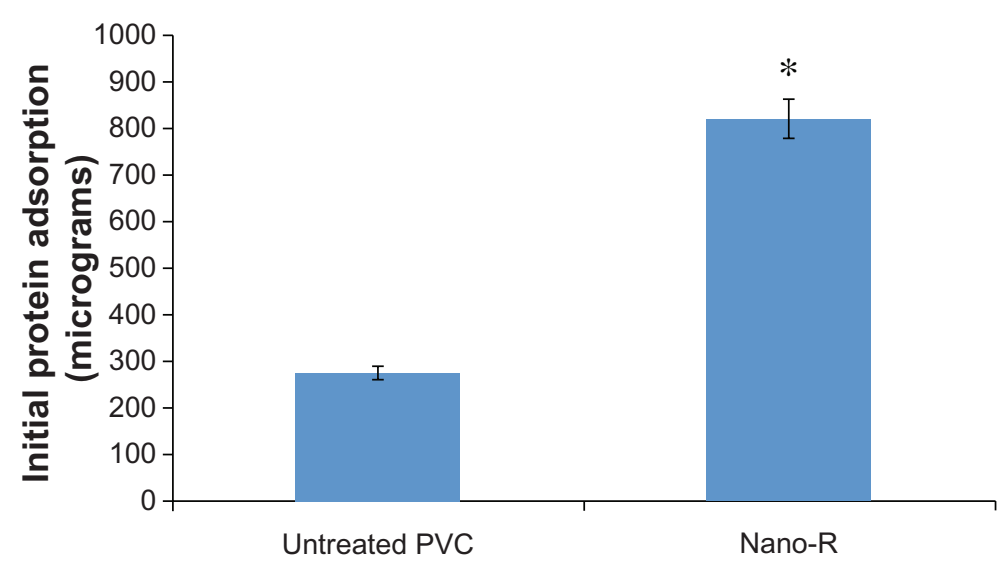

Figure 7 Increased total protein adsorption on nanomodified polyvinyl chloride (PVC) endotracheal tubes (Nano-R) compared with controls. Nano-R was modified with Rhizopus arrhisus.

Notes: Data $=$ mean \pm scanning electron microscopy; $N=3 ; * P<0.01$ compared with untreated.

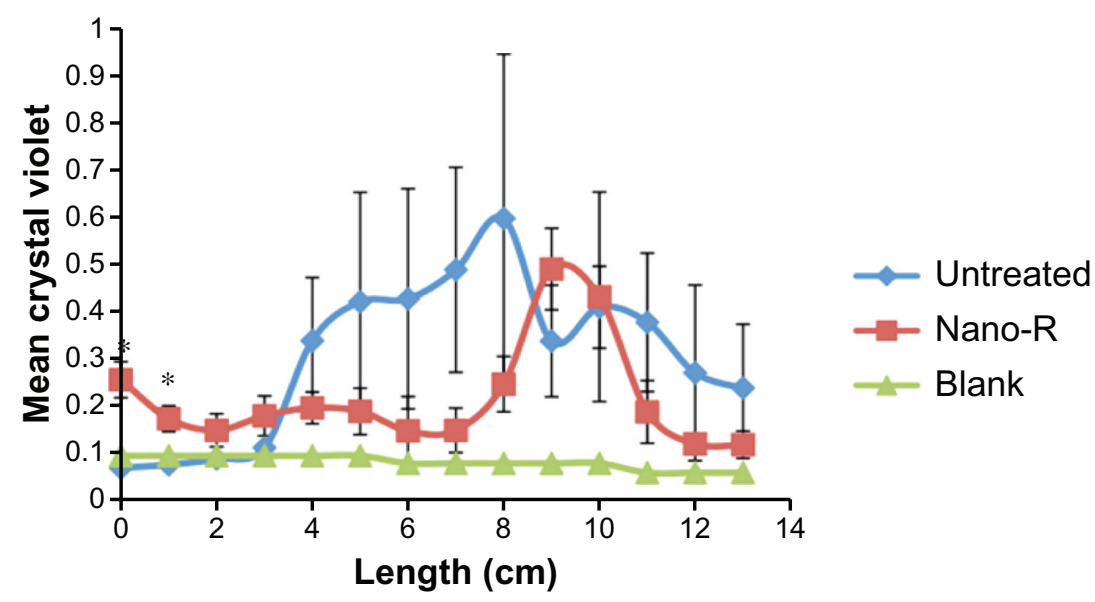

Figure 8 Dynamic lung system results for untreated tubes versus nanomodified polyvinyl chloride endotracheal tubes (ETTs): crystal violet stain; $N=3$ ( $x$-axis length = longitudinal ETT length); blank = sterile ETTs soaked in trypticase soy broth medium.

Notes: Error bars \pm I standard error; $* P<0.05$ compared with untreated ETTs at the same time points.

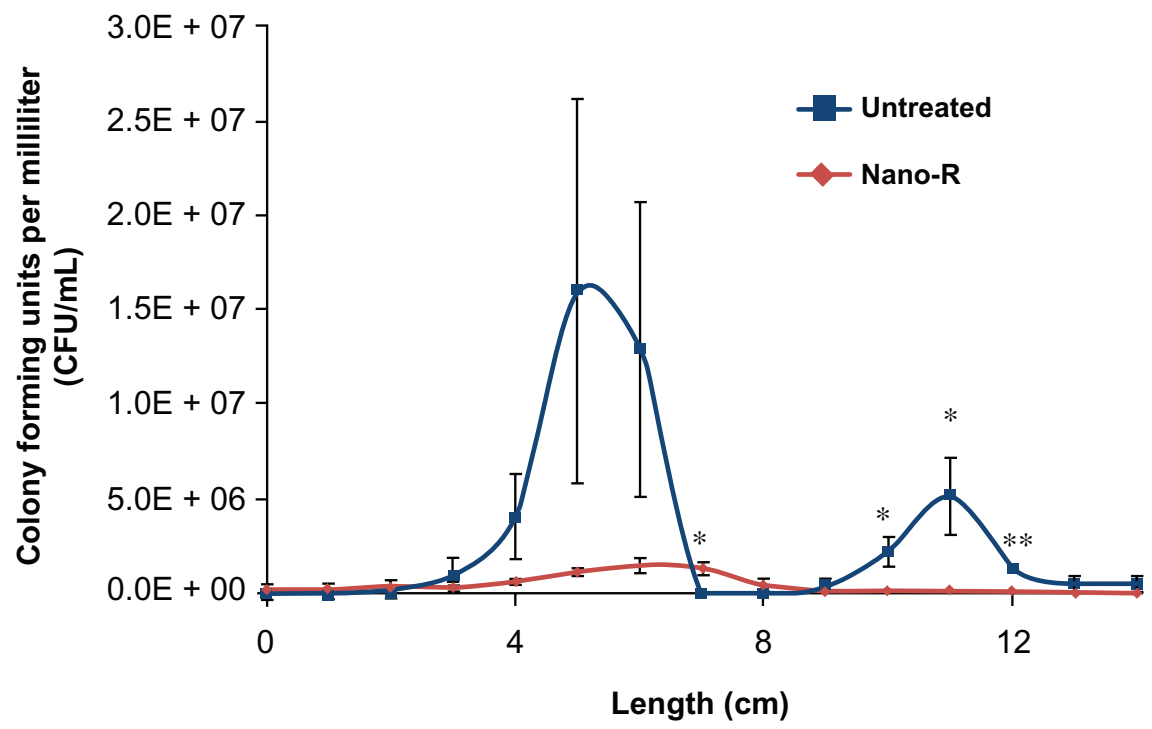

Figure 9 Dynamic lung system results for untreated versus nanomodified versus nanomodified polyvinyl chloride endotracheal tubes (ETTs): colony counts of Staphylococcus aureus; Notes: $\mathrm{N}=3$ ( $\mathrm{x}$-axis length = longitudinal ETT length); error bars \pm I standard error; $* P<0.05$ and $* * P<0.01$ compared with untreated ETTs at the same time points. 
A

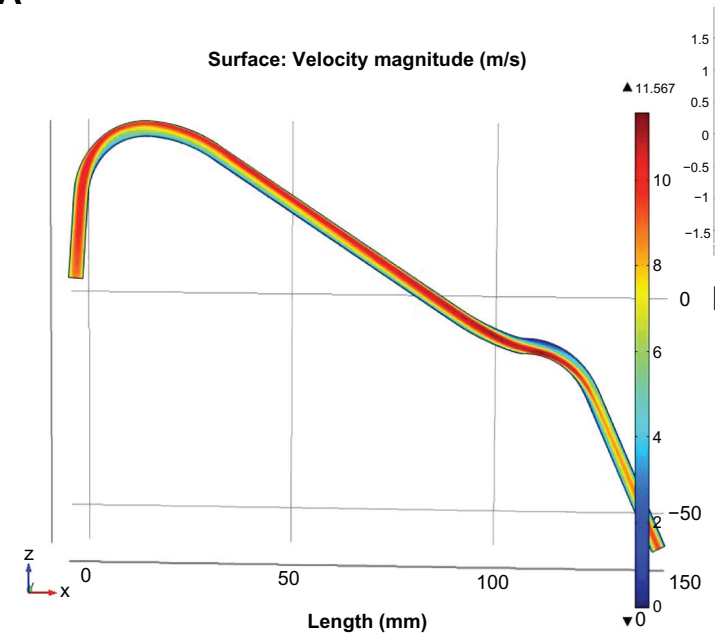

B

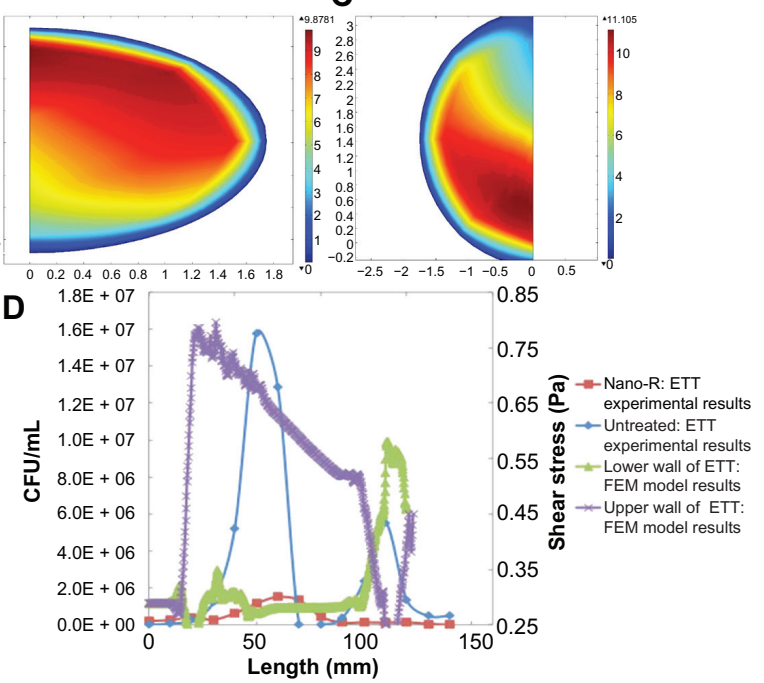

Figure 10 Field emission microscopy (FEM) model: (A) velocity magnitude longitudinal slice of ETT (B) velocity magnitude cross section: first curve, (C) velocity magnitude cross section: second curve, and (D) maximum shear stress versus bacterial density.

Note: Results show a correlation of shear stress to increased bacteria function for the first curve but not the second curve.

Abbreviations: CFU, colony-forming unit; ETT, endotracheal tube.

properties of biofilms (such as cell density) have been shown to be affected by fluid shear. ${ }^{37}$ High shear forces have been shown to favor the creation of tight, rounded microcolonies of bacteria. ${ }^{38}$ This data, coupled with the evidence of hydrodynamic effects on biofilm formation from the literature, suggested that an in-depth analysis of the forces on the ETTs is needed.

Results of the computational model showed that areas of low wall shear $(0.20 \mathrm{~Pa})$ along the lower wall of the endotracheal tube did correspond to experimental areas of high bacterial density. These values were compared with literature values for shear stress in the healthy lung, which can vary widely based upon diameter and flow rate but are between $0.0294 \mathrm{~Pa}$ and $0.1961 \mathrm{~Pa}$ in the trachea. ${ }^{39}$

However, shear stress appears to be only one of a number of contributing factors to bacterial location and growth in the ETT. A slightly clearer association was seen between particle location and bacterial numbers found in the experimental model; however, this still does not fully explain the mechanism of bacterial distribution in the system. This could be due to the limitations of the field emission microscopy model, which does not take into account interactions between bacteria, differences

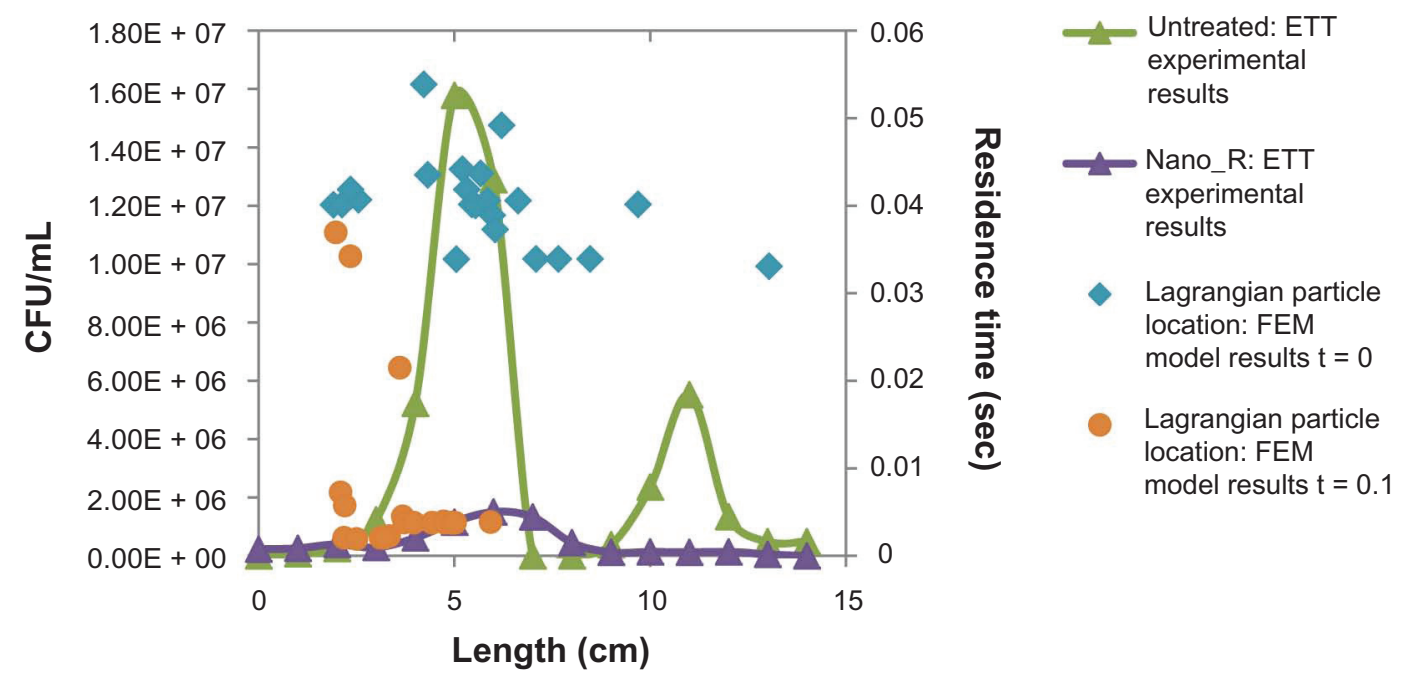

Figure I I Field emission microscopy (FEM) model. Particle distribution versus bacterial density.

Note: Results show increased particle (representing bacteria) residence time in both curves of the endotracheal tube (ETT).

Abbreviation: CFU, colony-forming unit. 


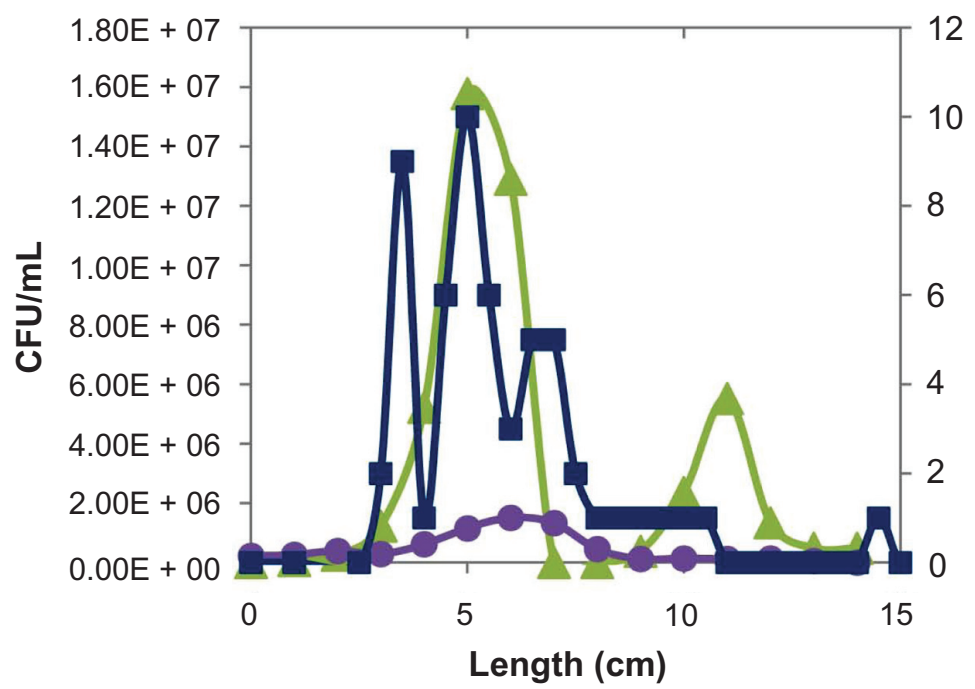

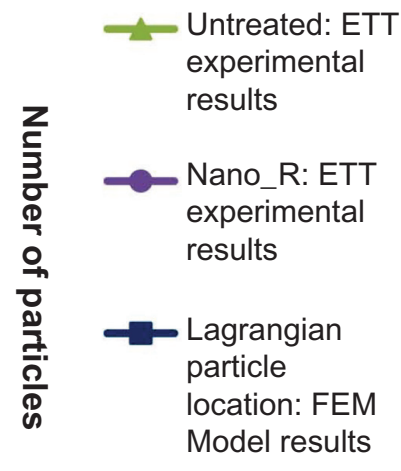

Figure 12 Field emission microscopy (FEM) model. Particle distribution versus bacterial density. Abbreviations: CFU, colony-forming unit; ETT, endotracheal tube.

in particle (bacteria) size, or interactions with the ETT walls. As in the static studies, the mechanism for the reduction on the nanomodified ETTs is unclear but is thought to be associated with reduced adhesion of the bacteria to the surface. This reduction could be due to altered initial protein interactions from TSB or to surface energy changes, both of which can affect bacterial adhesion. ${ }^{3}$ These mechanisms all require further analysis. Thus, future efforts will concentrate on the creation of a larger continuum model to better analyze transport of bacteria, residence time within the ETT, and bacterial interactions with the wall, all in an effort to fully understand spatial locations of bacteria functions on ETTs and the observed decreased bacteria functions on the nanomodified ETTs.

\section{Conclusion}

This study showed that chemical etching techniques can create nanorough surface features on PVC ETTs to suppress $S$. aureus growth. Compared with previous static studies, ${ }^{8}$ the present dynamic study showed a much greater decrease in bacteria function on nanomodified ETTs compared with unmodified ETTs. In addition, dynamic airflow conditions had an effect on both the concentration and location of bacterial growth spatially on the ETTs. A more accurate understanding of the areas of biofilm formation within the ETT could not only lead to better sampling and diagnosis of VAP but also improve clinical procedures such as suctioning and cleaning of ETTs.

In vitro modeling of nanomodified ETTs under dynamic conditions may further provide useful insights into their antimicrobial effectiveness. The differences recorded along the length of the tube suggest that flow and continuous contamination play a significant role in bacterial colonization. This provides further evidence that static testing may not reveal the important interactions at the surface of such devices in vivo. The results of both the static and dynamic experiments suggest that nanomodified tubes, as created here, could provide clinicians with an effective and inexpensive tool to combat hospital-acquired infections like VAP and should be studied in greater depth. Importantly, the nanomodified tubes decreased $S$. aureus growth by only changing the degree of nanofeatures, not by altering chemistry or using antibiotics.

\section{Acknowledgments}

The authors would like to thank the Hermann Foundation, the RI Science and Technology Advisory Council, and the NSF GK-12 for funding.

\section{Disclosure}

The authors declare no conflict of interest with this manuscript.

\section{References}

1. Brilli RJ, Sparling KW, Lake MR. The business case for preventing ventilator-associated pneumonia in pediatric intensive care unit patients. Jt Comm J Qual Patient Saf. 2008;34:629-638.

2. Richards MJ, Edwards JR, Culver DH, Gaynes RP, the National Nosocomial Infections Surveillance System. Nosocomial infections in pediatric intensive care units in the United States. Pediatrics. 1999;103(4):e39.

3. Baltimore RS. The difficulty of diagnosing VAP. Pediatrics. 2003;112: 1420-1421.

4. Irwin, RS, Rippe JM. Irwin and Rippe's intensive care medicine Philadelphia, PA: Wolters Kluwer Health/Lippincott Williams and Wilkins, 2008.

5. Gaynes R, Edwards JR. Overview of nosocomial infections caused by gram-negative bacilli. Clin Infect Dis. 2005;41:848-854. 
6. Koerner RJ. Contribution of endotracheal tubes to the pathogenesis of ventilator-associated pneumonia. J Hosp Infect. 1997;35:83-89.

7. Tarquinio KM, Kothurkar NK, Goswami DY. Bactericidal effects of silver plus titanium dioxide-coated endotracheal tubes on Pseudomonas aeruginosa and Staphylococcus aureus. Int J Nanomedicine. 2010; 5:177-183.

8. Cardinal P, Jessamine P, Carter-Snell C, Morrison S, Jones G. Contribution of water condensation in endotracheal tubes to contamination of the lungs. Chest. 1993;104(1):127-129.

9. Murthy SK. Nanoparticles in modern medicine: state of the art and future challenges. Int J Nanomedicine. 2007;2:129-141.

10. Machado MC, Cheng D, Tarquinio KM, Webster TJ. Nanotechnology: pediatric applications. Pediatr Res. 2010;67(5):500-504.

11. Taylor EN, Webster TJ. The use of superparamagnetic nanoparticles for prosthetic biofilm prevention. Int J Nanomedicine. 2009;4:145-152.

12. Tran PA, Webster TJ. Selenium nanoparticles inhibit Staphylococcus aureus growth. Int J Nanomedicine. 2011;6:1553-1558.

13. Taylor EN, Webster TJ. Reducing infections through nanotechnology and nanoparticles. Int J Nanomedicine. 2011;6:1463-1473.

14. Tran N, Mir A, Mallik D. Bactericidal effect of iron oxide nanoparticles on Staphylococcus aureus. Int J Nanomedicine. 2010;5: $277-283$.

15. Juan L, Zhimin Z, Anchun M, Lei L, Jingchao Z. Deposition of silver nanoparticles on titanium surface for antibacterial effect. Int J Nanomedicine. 2010;5:261-267.

16. Sanvicens N, Marco MP. multifunctional nanoparticles properties and prospects for their use in human medicine. Trends Biotechnol. 2008;26:425-433.

17. Klein J. Probing the interactions of proteins and nanoparticles. Proc Natl Acad Sci U S A. 2007;104:2029-2030.

18. Puckett $S$, Pareta R, Webster TJ. Nano rough micron patterned titanium for directing osteoblast morphology and adhesion. Int J Nanomedicine. 2008:3:229-241.

19. Gongadze E, Kabaso DD, Bauer S, et al. Adhesion of osteoblasts to a nanorough titanium implant surface. Int J Nanomedicine. 2011;6: 1801-1816.

20. Heidari S, Azhdadi SN, Asefnezhad A, Sadraeian M, Montazeri M, Biazar E. The relationship between cellular adhesion and surface roughness for polyurethane modified by microwave plasma radiation. Int $J$ Nanomedicine. 2011;6:641-647.

21. Dalby MJ. Cellular response to low adhesion nanotopgraphies. Int $J$ Nanomedicine. 2007;2:373-381.

22. Liu H, Webster TJ. Nanomedicine for implants: a review of studies and necessary experimental tools. Biomaterials. 2006;28:354-369.

23. Lichter JA, Thompson MT, Delgadillo M, Nishikawa T, Rubner MF, Van Vliet KJ. Substrata mechanical stiffness can regulate adhesion of viable bacteria. Biomacromolecules. 2008;9(6):1571-1578.

24. Diaz C, Cortizo MC, Schilardi PL, Saravia SGG, Mele MAFL. Influence of the nano-micro structure of the surface on bacterial adhesion. Mat Res. 2007;10(1):11-14.

25. Rupp CJ, Fux CA, Stoodley P. Viscoelasticity of Staphylococcus aureus biofilms in response to fluid shear allows resistance to detachment and facilitates rolling migration. Appl Environ Microbiol. 2005;71(4):2175-2178.
26. Berger SA, Talbot L. Flow in curved pipes. Annu Rev Fluid Mech. 1983; 15:461-512.

27. Rusconi R, Lecuyer S, Guglielmini L, Stone HA. Laminar flow around corners triggers the formation of biofilm streamers. $J$ R Soc Interface. 2010;7:1293-1299.

28. Donlan RM. Biofilms: microbial life on surfaces. Emerg Infect Dis. 2002;8:881-890.

29. Hartmann M, Guttmann J, Muller B, Hallmann T, Geiger K. Reduction of the bacterial load by the silver-coated endotracheal tube (SCET) a laboratory investigation. Technol Health Care. 1999;7: 359-370.

30. Jarreau PH, Louis B, Dassieu G, Desfrere L, Blanchard PW, Moriette G, et al. Estimation of inspiratory pressure drop in neonatal and pediatric endotracheal tubes. J Appl Physiol. 1999;87: $36-46$.

31. Rudolph CD. Diagnosis and management of children with feeding disorders. In: Gastrointestinal motility disorders in children. Hyman P, Di Lorenzo C, eds. New York: Academy Professional Information Services; 1994: 33-54.

32. Dean WR. The stream-line motion of fluid in a curved pipe. Phil Mag. 1928;5(7):673-695.

33. Dellinger RP, Jean S, Cinel I. Regional distribution of acoustic-based lung vibration as a function of mechanical ventilation mode. Crit Care. 2007;11:R26.

34. Tortora GJ, Funke BR, Case CL. Microbiology: an introduction. California: Benjamin Cummings; 1998.

35. Davis B, Dulbecco R, Eisen H, Ginsberg H. Bacterial physiology: microbiology. 2nd ed, Maryland: Harper and Row; 1973: 96-97.

36. Seil JT, Rubien NM, Webster TJ, Tarquinio KM. Comparison of quantification methods illustrates reduced Pseudomonas aeruginosa activity on nanorough polyvinyl chloride. $J$ Biomed Mater Res B. 2011;9B(1):1-7.

37. Katsikogianni M, Missirlis YF. Concise review of mechanisms of bacterial adhesion to biomaterials and of techniques used in estimating bacteria-material interactions. Eur Cell Mater. 2004;8:37-57.

38. Perkins J, Mouzakes J, Pereira R., Mannings S. Bacterial biofilm presence in pediatric tracheotomy tubes. Arch Otolaryngol Head Neck Surg. 2004;130(3):339-343.

39. Nucci G, Suki B, Lutchen K. Modeling airflow-related shear stress during heterogeneous constriction and mechanical ventilation. $J$ Appl Physiol. 2003;95:348-356.

40. Park KD, Kim YS, Han DK, et al. Bacterial adhesion on PEG modified polyurethane surfaces. Biomaterials. 1998;19:851-859.

41. Van Loosdrecht MCM, Norde W, Lyklema J, Zehnder AJB. Hydrophobic and electrostatic parameters in bacterial adhesion. Aquat Sci. 1990;52:103-114.

42. Patel JD, Ebert M, Ward R, Anderson JM. S. epidermidis biofilm formation: effects of biomaterial surface chemistry and serum proteins. J Biomed Mater Res. 2007;80A:742-751.

43. Hulander M, Lundgren A, Berglin M, Ohrlander M, Lausmaa J, Elwing $\mathrm{H}$. Immune complement activation is attenuated by surface nanotopography. Int J Nanomedicine. 2011;6:2653-2666.
International Journal of Nanomedicine

\section{Publish your work in this journal}

The International Journal of Nanomedicine is an international, peerreviewed journal focusing on the application of nanotechnology in diagnostics, therapeutics, and drug delivery systems throughout the biomedical field. This journal is indexed on PubMed Central, MedLine, CAS, SciSearch ${ }^{\circledR}$, Current Contents ${ }^{\circledR} /$ Clinical Medicine,

\section{Dovepress}

Journal Citation Reports/Science Edition, EMBase, Scopus and the Elsevier Bibliographic databases. The manuscript management system is completely online and includes a very quick and fair peer-review system, which is all easy to use. Visit http://www.dovepress.com/ testimonials.php to read real quotes from published authors. 